\title{
Improvement in Physico-Chemical Properties of Kinnow (Citrus reticulata Blanco) after the Foliar Application with Micronutrients and Growth Regulators
}

\author{
Anjil Kumar*, Anis Mirza, Anshu Singh, Vikas, Jaihoon Rafie, \\ Praveen Kumar, Balwan Kumar and Parkash Verma
}

School of Agriculture, Roorkee college of Engineering, Roorkee, 247667, Uttarakhand, India *Corresponding author

\section{A B S T R A C T}

It was focused on effect of pruning, foliar application of micronutrients

Keywords

Kinnow, $\mathrm{ZnSO}_{4}$, RBD.

Article Info

Accepted:

07 September 2017

Available Online:

10 November 2017 (zinc sulphate, boron) and growth regulators $\left(\mathrm{GA}_{3}\right.$, NAA, Kinetin) on physico-chemical properties of Kinnow fruit during the present investigation. Thirteen treatments replicated thrice were arranged and applied with Randomised Block Design both in pruned and un-pruned conditions onto plants. The result reveals that the combine application of pruning, zinc sulphate $(250 \mathrm{ppm})$ and kinetin $(50 \mathrm{ppm})$ showed better performance significantly increases in the vesicle juice and total juice. And un-pruning, zinc sulphate $(250 \mathrm{ppm})$ and $\mathrm{GA}_{3}(50 \mathrm{ppm})$ has been significantly possible in the increasing of length, breadth and decreasing in peel percent.

\section{Introduction}

Citrus is believed to have originated in south China and the Cathay Sian ancient continent along with Kangdian, Sichuan, Indo-China peninsula and south of Yangtze River then spreaded into Australia, Africa and India according to theories of continental drift, the geological and ecological vicissitude. This fruit crops are cultivated in India which divided in four different zones i.e. central India (Madhya Pradesh, Maharashtra and Gujarat), southern India (Andhra Pradesh and Karnataka), north-western India (Punjab, Rajasthan, Haryana and western UP) and north-eastern India (Meghalaya, Assam and
Sikkim). Pruning is that practices which performed in associate acceptable manner to provide the plant such a form and size along these lines on yield the specified crops. The recent reviews have shown that pruning in citrus (from solstice to early autumn) is as vital as in deciduous fruit plants so as to get higher yield and sensible quality fruits additionally as lower incidence of greening illness. The nutrition constitutes an important component of successful and healthy citrus cultivation. An inadequate nutrition leads to the improper growth and reduced productivity of the citrus trees. The 
micronutrients on the other hand though are required in small amount but play a great role in plant metabolism. Pre-harvest fruit drop is significant reason of low yield in Punjab, this drop of fruit at different phases of fruit growth is during the lacking of nutrition, more irrigation, and excessive insect pest attack on the plants. Tree drops its fruit once the concentration of auxins decreases and therefore the concentration of abscissic acid will increase because the endogenous hormones and their balance play a modulating role within the mobilization of nutrients to the creation of new organs.

\section{Materials and Methods}

The present study entitled "Effect of pruning, micronutrients and PGRs on Kinnow mandarin fruits in Punjab condition' was conducted at Horticulture farm, Department of Horticulture, School of Agriculture in Lovely Professional University, Phagwara, District Jalandhar, Punjab during the year 2016-17.

\section{Physical and chemical parameters determination}

Three plant from each treatment were selected at random and tagged for recording the observations on the following Fruit length, Fruit breadth, Specific gravity, Peel (\%), Total segment/fruit (No.), Rag (\%), Single vesicle weight (gm), Vesicles weight/fruit (gm), Single vesicle juice (ml), Total juice/fruit (ml) \& Juice $\mathrm{pH}$ quality characteristics of Kinnow fruit. The data were averaged and expressed per plant.

\section{Statistical data}

Data analysis is done through Randomized Block Design as advocated by Gomez and Gomez (1986). Overall significance of differences in the treatments is tested by using critical differences (C.D) at 5\% level of significance. The data obtained from the experiment is statistically analyzed for Analysis of Variance (ANOVA).

\section{Results and Discussion}

The maximum length of fruit $(7.31 \mathrm{~cm})$ was noted in the $T_{7}$ followed by the $T_{10}$ and $T_{6}$ $(6.94 \mathrm{~cm}, 6.85 \mathrm{~cm})$ and the minimum fruit length $(4.8 \mathrm{~cm})$ noted in $\mathrm{T}_{1}$ (Table 1$)$. Hesami et al., (2012) found that treatment of zinc outcomes about the most astounding fruit size of date. Use of various development controllers [GA and NAA alone and in combination] on "Pera" orange had no impact on the parameters of fruit advancement like fruit length, breadth and mass (Almeida et al., 2004). The maximum fruit breadth $(8.81 \mathrm{~cm})$ was observed in the $T_{7}$ followed by the $T_{10}$ and $\mathrm{T}_{3}(8.65 \mathrm{~cm}, 8.57 \mathrm{~cm})$ and minimum fruit breadth $(6.53 \mathrm{~cm})$ noted in $\mathrm{T}_{1}$. Ahmad et al., (1995) detailed that boron and zinc foliar application on orange upgraded fruit yield, fruit weight and breadth, total soluble solid and total sugars (Table 2). The use of $\mathrm{GA}_{3}$ has been accounted for to enhance the fruit development in Nagpur mandarin by Huchche (2005). The maximum specific gravity (1.02) was recorded in the $T_{11}$ followed by $T_{13}(1.01)$ and minimum (0.93) noted in $\mathrm{T}_{7}$. These outcomes are also correlated with the findings by Basker (1966). The maximum peel $(29.59 \%)$ was obtained in $\mathrm{T}_{9}$ followed by $\mathrm{T}_{11}$ and $\mathrm{T}_{13}(28.89 \%, 28.84 \%)$ and minimum peel $(22.36 \%)$ noted in $\mathrm{T}_{7}$. This is in agreement with Sharma and Randhawa (1966) who reported that $\mathrm{GA}_{3}$ at $50 \mathrm{ppm}$ decreased rind percentage of sweet lime. The maximum total segment (11.77) was obtained in the $\mathrm{T}_{4}$ followed by the $\mathrm{T}_{11}$ and $\mathrm{T}_{3}(11.11,10.99)$ and minimum segment (9.66) in the $\mathrm{T}_{10}$. Bhatnagar et al., (2005) which is almost similar to the present findings (Table 3 ). 
Table.1 Effect of pruning, micronutrients and plant growth regulators on the physico-chemical properties of Kinnow

\begin{tabular}{|c|c|c|c|c|}
\hline Treatments & Fruit length(cm.) & Fruit breadth $(\mathrm{cm})$. & Specific gravity & Peel (\%) \\
\hline $\mathbf{T}_{1}\left(\mathbf{P}_{1}+\mathrm{M}_{1}+\mathrm{G}_{1}\right)$ & 4.80 & 6.53 & 0.97 & 22.51 \\
\hline $\mathbf{T}_{2}\left(\mathbf{P}_{1}+\mathbf{M}_{1}+\mathbf{G}_{2}\right)$ & 6.46 & 8.15 & 0.95 & 23.43 \\
\hline $\mathbf{T}_{3}\left(\mathbf{P}_{1}+\mathbf{M}_{1}+\mathbf{G}_{3}\right)$ & 6.73 & 8.57 & 0.97 & 23.87 \\
\hline $\mathbf{T}_{4}\left(\mathbf{P}_{1}+\mathbf{M}_{2}+\mathbf{G}_{1}\right)$ & 6.39 & 8.01 & 0.99 & 26.45 \\
\hline $\mathbf{T}_{5}\left(\mathbf{P}_{1}+\mathbf{M}_{2}+\mathbf{G}_{2}\right)$ & 6.22 & 7.59 & 0.98 & 25.25 \\
\hline $\mathbf{T}_{6}\left(\mathbf{P}_{1}+\mathbf{M}_{2}+\mathbf{G}_{3}\right)$ & 6.85 & 8.30 & 0.95 & 25.76 \\
\hline $\mathbf{T}_{7}\left(\mathbf{P}_{2}+\mathbf{M}_{1}+\mathbf{G}_{1}\right)$ & 7.31 & 8.81 & 0.93 & 22.36 \\
\hline $\mathbf{T}_{8}\left(\mathbf{P}_{2}+\mathbf{M}_{1}+\mathbf{G}_{2}\right)$ & 6.47 & 8.31 & 0.96 & 27.90 \\
\hline$T_{9}\left(P_{2}+M_{1}+G_{3}\right)$ & 6.53 & 8.04 & 0.93 & 29.59 \\
\hline$T_{10}\left(P_{2}+M_{2}+G_{1}\right)$ & 6.94 & 8.65 & 0.98 & 27.34 \\
\hline $\mathbf{T}_{11}\left(\mathbf{P}_{2}+\mathbf{M}_{2}+\mathbf{G}_{2}\right)$ & 6.82 & 8.55 & 1.02 & 28.90 \\
\hline $\mathbf{T}_{12}\left(\mathbf{P}_{2}+\mathrm{M}_{2}+\mathbf{G}_{3}\right)$ & 6.55 & 8.16 & 0.93 & 23.09 \\
\hline$T_{13}$ (Control) & 6.43 & 7.49 & 1.01 & 28.84 \\
\hline C.D. & 0.70 & 0.64 & NS & NS \\
\hline SE(m) & 0.24 & 0.22 & 0.04 & 1.86 \\
\hline $\operatorname{SE}(d)$ & 0.33 & 0.31 & 0.06 & 2.62 \\
\hline C.V. & 6.35 & 4.67 & 6.96 & 12.46 \\
\hline
\end{tabular}

Table.2 Effect of pruning, micronutrients and plant growth regulators on the physico-chemical properties of Kinnow

\begin{tabular}{|c|c|c|c|c|}
\hline Treatments & $\begin{array}{l}\text { Total } \\
\text { segment/fruit(No.) }\end{array}$ & $\operatorname{Rag}(\%)$ & $\begin{array}{l}\text { Single vesicle } \\
\text { weight }\end{array}$ & Vesicles weight/fruit \\
\hline$T_{1}\left(P_{1}+M_{1}+G_{1}\right)$ & 10.88 & 1.41 & 19.24 & 156.63 \\
\hline $\mathbf{T}_{2}\left(\mathbf{P}_{1}+\mathbf{M}_{1}+\mathbf{G}_{2}\right)$ & 10.55 & 1.14 & 19.42 & 169.58 \\
\hline $\mathbf{T}_{3}\left(\mathbf{P}_{1}+\mathbf{M}_{1}+\mathbf{G}_{3}\right)$ & 10.99 & 0.95 & 20.58 & 196.33 \\
\hline $\mathbf{T}_{4}\left(\mathbf{P}_{1}+\mathbf{M}_{2}+\mathbf{G}_{1}\right)$ & 11.77 & 1.43 & 14.24 & 142.44 \\
\hline$T_{5}\left(P_{1}+M_{2}+G_{2}\right)$ & 10.89 & 1.33 & 14.61 & 133.89 \\
\hline $\mathbf{T}_{6}\left(\mathbf{P}_{1}+\mathbf{M}_{2}+\mathbf{G}_{3}\right)$ & 10.44 & 1.33 & 20.29 & 173.71 \\
\hline $\mathbf{T}_{7}\left(\mathbf{P}_{2}+\mathbf{M}_{1}+\mathbf{G}_{1}\right)$ & 10.44 & 1.80 & 19.39 & 187.13 \\
\hline $\mathbf{T}_{8}\left(\mathbf{P}_{2}+\mathbf{M}_{1}+\mathbf{G}_{2}\right)$ & 10.66 & 1.54 & 20.34 & 153.34 \\
\hline$T_{9}\left(P_{2}+M_{1}+G_{3}\right)$ & 9.89 & 1.43 & 17.24 & 144.09 \\
\hline $\mathbf{T}_{10}\left(\mathbf{P}_{2}+\mathrm{M}_{2}+\mathrm{G}_{1}\right)$ & 9.66 & 1.59 & 20.51 & 177.11 \\
\hline $\mathrm{T}_{11}\left(\mathrm{P}_{2}+\mathrm{M}_{2}+\mathrm{G}_{2}\right)$ & 11.11 & 1.34 & 17.67 & 168.95 \\
\hline $\mathbf{T}_{12}\left(\mathbf{P}_{2}+\mathbf{M}_{2}+\mathbf{G}_{3}\right)$ & 9.88 & 1.87 & 22.07 & 172.92 \\
\hline $\mathbf{T}_{13}$ (Control) & 9.77 & 1.50 & 13.48 & 121.20 \\
\hline C.D. & NS & NS & NS & NS \\
\hline SE(m) & 0.47 & 0.27 & 2.36 & 16.09 \\
\hline SE(d) & 0.67 & 0.38 & 3.34 & 22.76 \\
\hline C.V. & 7.75 & 32.66 & 22.23 & 17.28 \\
\hline
\end{tabular}


Table.3 Effect of pruning, micronutrients and plant growth regulators on the physico-chemical properties of Kinnow

\begin{tabular}{|c|c|c|c|}
\hline Treatments & Single vesicle juice (ml) & Total juice/fruit (ml) & Juice pH \\
\hline$T_{1}\left(P_{1}+M_{1}+G_{1}\right)$ & 10.94 & 119.70 & 3.92 \\
\hline $\mathbf{T}_{2}\left(\mathbf{P}_{1}+\mathbf{M}_{1}+\mathbf{G}_{2}\right)$ & 13.53 & 131.94 & 3.81 \\
\hline$T_{3}\left(P_{1}+M_{1}+G_{3}\right)$ & 14.43 & 159.51 & 4.02 \\
\hline$T_{4}\left(P_{1}+M_{2}+G_{1}\right)$ & 7.51 & 111.01 & 3.88 \\
\hline$T_{5}\left(P_{1}+M_{2}+G_{2}\right)$ & 10.80 & 100.99 & 3.67 \\
\hline$T_{6}\left(P_{1}+M_{2}+G_{3}\right)$ & 14.04 & 147.33 & 3.97 \\
\hline $\mathbf{T}_{7}\left(\mathbf{P}_{2}+\mathbf{M}_{1}+\mathbf{G}_{1}\right)$ & 10.89 & 144.11 & 4.03 \\
\hline $\mathbf{T}_{8}\left(\mathbf{P}_{2}+\mathbf{M}_{1}+\mathbf{G}_{2}\right)$ & 12.10 & 118.18 & 4.03 \\
\hline$T_{9}\left(P_{2}+M_{1}+G_{3}\right)$ & 9.60 & 112.36 & 3.97 \\
\hline $\mathbf{T}_{10}\left(\mathbf{P}_{2}+\mathbf{M}_{2}+\mathbf{G}_{1}\right)$ & 14.04 & 142.29 & 4.19 \\
\hline $\mathbf{T}_{11}\left(\mathbf{P}_{2}+\mathbf{M}_{2}+\mathbf{G}_{2}\right)$ & 12.47 & 130.07 & 3.89 \\
\hline $\mathbf{T}_{12}\left(\mathbf{P}_{2}+\mathbf{M}_{2}+\mathbf{G}_{3}\right)$ & 13.02 & 127.71 & 4.19 \\
\hline $\mathbf{T}_{13}$ (Control) & 6.58 & 73.92 & 4.14 \\
\hline C.D. & 4.92 & 38.86 & 0.17 \\
\hline SE(m) & 1.68 & 13.23 & 0.06 \\
\hline $\mathbf{S E}(\mathrm{d})$ & 2.37 & 18.72 & 0.08 \\
\hline C.V. & 25.17 & 18.40 & 2.53 \\
\hline
\end{tabular}

Experimental Details

\begin{tabular}{l}
\hline Variety - Kinnow Local \\
\hline Rootstock- JattiKhatti \\
Scion - Mandarin \\
Age - 9 years \\
Spacing - 6m X 6 m \\
Number of treatments - 13 \\
Number of replications - 3 \\
Total number of samples-- $13 \times 3=39$ \\
Design - Randomized Block Design (RBD) \\
\hline
\end{tabular}

Treatment Details

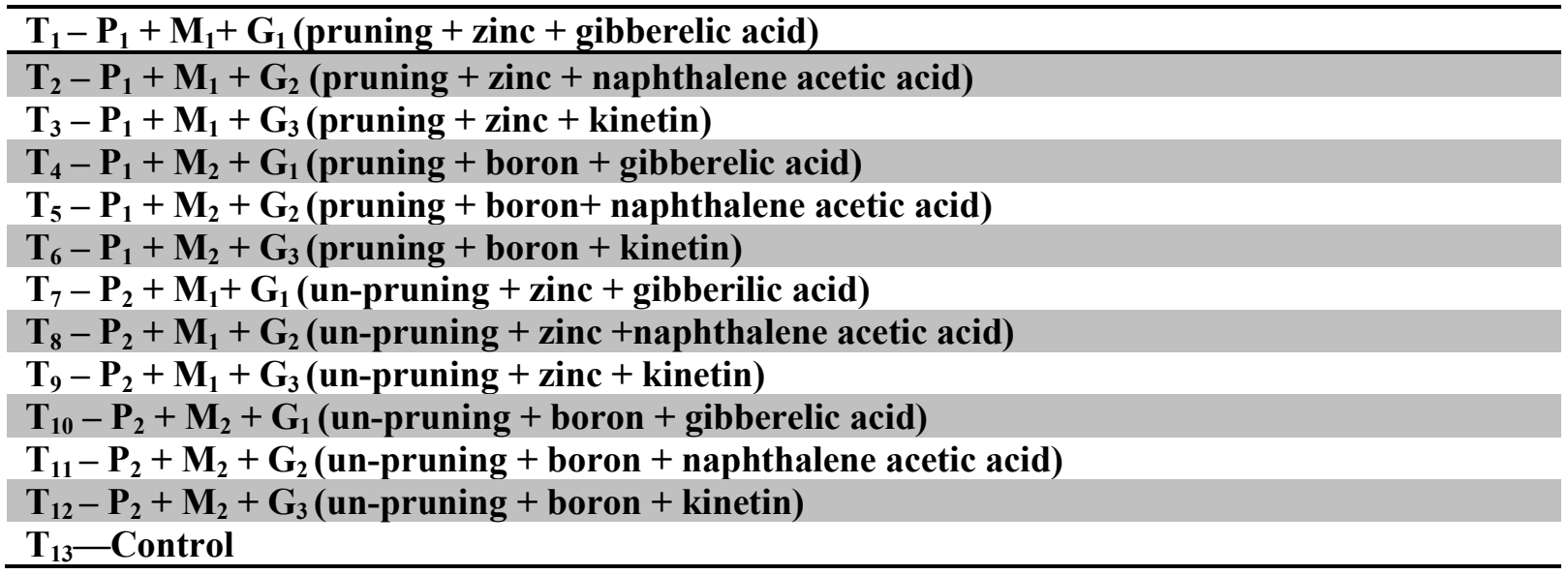


The maximum rag percentage (1.87) observed in $\mathrm{T}_{12}$ followed by $\mathrm{T}_{7}$ and $\mathrm{T}_{10}(1.8,1.59)$. And minimum rag percentage $(0.95)$ gated in $T_{3}$. $\mathrm{GA}_{3}$ and kinetin significantly diminished the rag mass (\%) as compared with control. This may be during the increased vascularization in the pedicel (Guardiola et al., 1993). The maximum single vesicle weight $(22.07 \mathrm{gm})$ founded in $T_{12}$ followed by the $T_{3}$ and $T_{10}$ (20.58gm, 20.51gm) and minimum (13.48gm) observed in the $T_{13}$. This is in agreement with Brent et al., (1990). The maximum vesicles weight $(196.33 \mathrm{gm})$ noted in $\mathrm{T}_{3}$ followed by $\mathrm{T}_{7}$ and $\mathrm{T}_{10} \quad(187.13 \mathrm{gm}, 177.11 \mathrm{gm})$ and minimum vesicles weight (121.97gm) observed in $\mathrm{T}_{13}$.Bhatnagar et al., (2005) which is almost similar to the present findings. The maximum single vesicle juice (14.43ml) obtained in $\mathrm{T}_{3}$ followed by the $\mathrm{T}_{6}$ and $\mathrm{T}_{10}(14.04 \mathrm{ml}, 14.04 \mathrm{ml})$ and minimum vesicle juice $(6.58 \mathrm{ml})$ recorded in $\mathrm{T}_{13}$. This is in agreement with Bhatnagar et al., (2005).

And the maximum juice $(159.51 \mathrm{ml})$ per fruit founded in $T_{3}$ followed by $T_{6}$ and $T_{7}$ $(147.33 \mathrm{ml}, 144.11 \mathrm{ml})$. And minimum (73.92ml) observed in $\mathrm{T}_{13}$. Jain et al., (2014) reported that by the spray of $\mathrm{GA}_{3}$ on Nagpur mandarin gated maximum juice recovery through the fruits. Rama and Bose (2000) reported that the higher juice content in Citrus reticulata observed by the spray of micronutrients. The maximum juice $\mathrm{pH}$ (4.19) was founded in $\mathrm{T}_{10}$ followed by $\mathrm{T}_{12}$ and $\mathrm{T}_{13}$ (4.18, 4.14). And minimum juices $\mathrm{pH}$ (3.67) was founded in the $\mathrm{T}_{5}$. Moslehi et al., (2011) recorded that the utilization of micronutrients especially zinc significantly decreased $\mathrm{pH}$ as compared to control.

\section{Acknowledgement}

I am extremely grateful to my advisor Dr. Anis Mirza and Department of Horticulture LPU, Punjab for providing all facilities related to my research work.

\section{References}

Ahmad, M., Abdel, F.M.,Hegab, M.Y. (1995) Effect of urea, some micronutrients, and growth regulators foliar spray on the yield, fruit quality, and some vegetative of, Washington navel orange trees. Hortscience, 30(4): 774.

Almeida, I.M.L., Rodrigues, J.D. and Ono, E.O. (2004) Application of plant growth regulators at pre-harvest for fruit development of 'Pera' oranges. Braz. Arch. Biol. Technol., 47(4): 511-520.

Basker, H. B. (1966) Presumptive specific gravity of concentrated citrus juices. $J$. Sci. food and agri., 17: 539-541.

Bhatnagar, P., Sharma, M.K. and Singh, J. (2005) Analysis of fruitqualityof Kinnow mandarin hybrid in arid irrigated areas of Rajasthan, Hort Flora Res. Spec., 4(1): 52-55.

Brent, T., Jones, D., Galletta, P.D. (1990) Juice Vesicle Populations in Citrus Fruit. Bot. Gazette. 151(1): 9.

Gomez, K.A. and Gomez, A.A. (1986) Statistical procedure for agriculture research. Wiley Inter sci. Pub. Singapore, pp. 298-308.

Guardiola, J.L., Barres, M.T., Albert, C. and Garcia-Luis, A. (1993) Effect of exogeneous growth regulators on fruit development in Citrus unshiu. Ann. Bot., 71: 169-176.

Hesami, A., Taghados, A., Mojab, S. (2012) Interaction between $\mathrm{Zn}$ and $\mathrm{Mn}$ for the physicochemical traits of date fruits cv. Kabkab. National Iranian Conference of Date, Shahid Bahonar University of Kerman, Horticulture Research Center, Kerman, Iran.

Huchche, A.D. (2005) Fruit size improvement in Nagpur mandarin. Annual Report 2004-2005 National Research Centre for Citrus. Nagpur.

Jain, M.C., Choudhary, H.D., Sharma, M.K. and Singh, B. (2014) Yield and quality 
attributes of Nagpur mandarin as effect by use of different plant growth regulators. Environ. Eco, 32: 11411145 .

Moslehi, A., Fekri, M., BeigMohammadi, A. (2011) Effect of Fe, $\mathrm{Zn}$ and $\mathrm{Cu}$ spray on increasing the quality and yield of pomegranate. National Conference on Pomegranate, Ferdowsi University of
Mashhad, Iran.

Rama, R.A. and Bose, T.K. (2000) Effect of foliar application of magnesium and micronutrients on growth, yield and quality of mandarin (Blanco). Indian $\mathrm{J}$. of Hort., 57(3): 215-20.

Sharma, R.B. and Randhawa, G. (1966) Studies on fruit set and fruit drop in citrus. Indian J. Hort., 23(1-2): 12-20.

\section{How to cite this article:}

Anjil Kumar, Anis Mirza, Anshu Singh, Vikas, Jaihoon Rafie, Praveen Kumar, Balwan Kumar and Parkash Verma. 2017. Improvement in Physico-Chemical Properties of Kinnow (Citrus reticulata Blanco) after the Foliar Application with Micronutrients and Growth Regulators. Int.J.Curr.Microbiol.App.Sci. 6(11): 389-394. doi: https://doi.org/10.20546/ijcmas.2017.611.044 